\title{
THE ROLE OF THE GENERAL PRACTITIONER IN THE CAMPAIGN AGAINST THE MUMPS
}

\author{
Tsv. Valentinova, M. Karcheva* \\ Sector , General Medicine”, \\ *Sector ,Epidemiology, Parasitology and Tropical Medicine”, \\ Medical University - Pleven
}

\section{SUMMARY}

During the last 3-4 years the number of the sick with mumps in Bulgaria increased considerably. Therefore, the scientists focused on two major issues in the campaign against the disease. Aims: To study the opinion of the general practitioners concerning the issues occurring during immunization with the MMR (measles, mumps, rubella) triple vaccine, diagnostics and treatment of already existing mumps among their patients. Materials: The participants in the research have been selected at random among the general practitioners specializing in general medicine at the Medical University-Pleven. Conclusion: The general practitioners, considered to be the first unit in the health care system of the country, are the basic participants in the prevention of that disease by executing the immunization schedule. measures

Key words: mumps, general practitioners, control

\section{INTRODUCTION}

During the last 3-4 years the number of the sick with mumps in Bulgaria increased considerably [5]. Therefore, the scientists focused on two major issues in the campaign against the disease $[3,4,6]$. The first one had to do with the early and active diagnostics of the disease. It is known that up to $50 \%$ of the sick have no symptoms thus unconsciously spreading the infection directly on other people. The second issue had to do with a massive specific immune prevention. Despite the high degree of vaccination coverage in the country, the immune prevention has not reached maximum epidemiologic effectiveness. The general practitioners, considered to be the first unit in the health care system of the country, are directly related to performing both activities, more precisely: timely determination of the diagnosis and undertaking control measures, as well as disease prevention by performing immunization according to the country immunization schedule $[1,2]$.

\section{AIMS}

To study the opinion of the general practitioners concerning the issues occurring during immunization with the MMR (measles, mumps, rubella) triple vaccine, diagnostics and treatment of already existing mumps among their patients.

\section{MATERIALAND METHODS}

The participants in the research have been selected at random among the general practitioners specializing in general medicine at the Medical University-Pleven. The group comprises 71 participants being approximately $1 / 5$ of the general practitioners specializing at the University at the moment.

A direct anonymous enquiry was conducted. The questionnaire contained open, closed and semi-closed questions in order to study the opinion, attitude and evaluation of the interviewed people with respect to the features in question. The data of the research were processed with the help of the software statistics packages Excel and Statgraphics v.2.0.

\section{RESULTS AND DISCUSSIONS}

Table 1. Socio-demographic characteristics of the studied persons

\begin{tabular}{|l|c|c|}
\hline Feature & $\begin{array}{c}\text { Number } \\
\text { (n) }\end{array}$ & $\begin{array}{c}\text { Relative } \\
\text { share (\%) }\end{array}$ \\
\hline Sex & 26 & 37 \\
1. Men & 45 & 63 \\
2. Women & & \\
\hline Experience & 0 & \\
1. Up to 5 years & 20 & 28 \\
2. From 6 to 15 years & 51 & 72 \\
3. Over 15 years & & \\
\hline Speciality & 38 & 53 \\
1. No speciality & 20 & 28 \\
2. Internal Diseases & 8 & 12 \\
3. Paediatrics & 4 & 6 \\
4. Obstetrics and Gynaecology & 1 & 1 \\
5. Surgery & & \\
\hline Size of patient's & 19 & 27 \\
1. Up to 1000 & 16 & 22 \\
2. From 1000 to 1500 & \\
\hline
\end{tabular}




\begin{tabular}{|c|c|c|}
\hline $\begin{array}{l}\text { 3. From } 1500 \text { to } 3000 \\
\text { 4. Over } 3000\end{array}$ & $\begin{array}{r}32 \\
4\end{array}$ & $\begin{array}{r}45 \\
6\end{array}$ \\
\hline $\begin{array}{l}\text { Treated populated area } \\
\text { 1. Village } \\
\text { 2. Town with population } \\
\text { below } 100000 \text { residents } \\
\text { 3. Town with population } \\
\text { over } 100000 \text { residents }\end{array}$ & 42 & 59 \\
\hline
\end{tabular}

It became clear from the answers provided by the doctors to the questionnaire that most of them are partially familiar with the tendencies in the propagation of the mumps - $66 \% ; 17 \%$ determine themselves as profoundly familiar with the issue and another $17 \%$ admit to have no information whatsoever about the problem. The presence or lack of any information depends neither on their experience $(\chi=5,67$; $\mathrm{p}=0,0589)$ nor on their workplace $(\chi=5,45 ; \mathrm{p}=0,2446)$.

The major impediments concerning the immune prevention of the disease arise from the fact that patients invited by their GP are reluctant to receive immunization (according to $17 \%$ of the interviewed). This is mostly observed among the patients of Gypsy origin.

A large number of doctors $(20 \%)$ - report to have cases when patients refused to have the triple vaccine administered. The reasons are shown in Fig. 1.

Fig. 1. Motives to refuse immunization

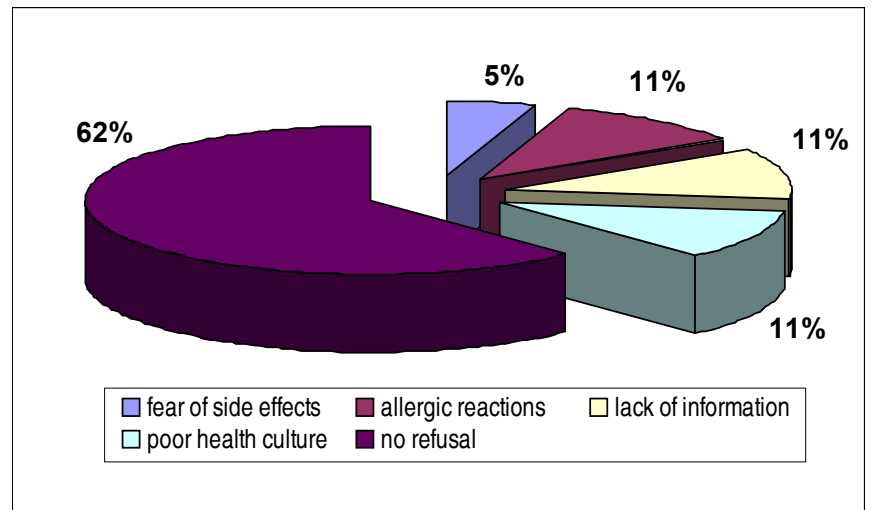

The experience of the participants in the research showed that the fear of side effects from the vaccine are groundless $-80 \%$ report to have observed no such reaction at all - Fig. 2.
Fig. 2. Adverse reactions after vaccination

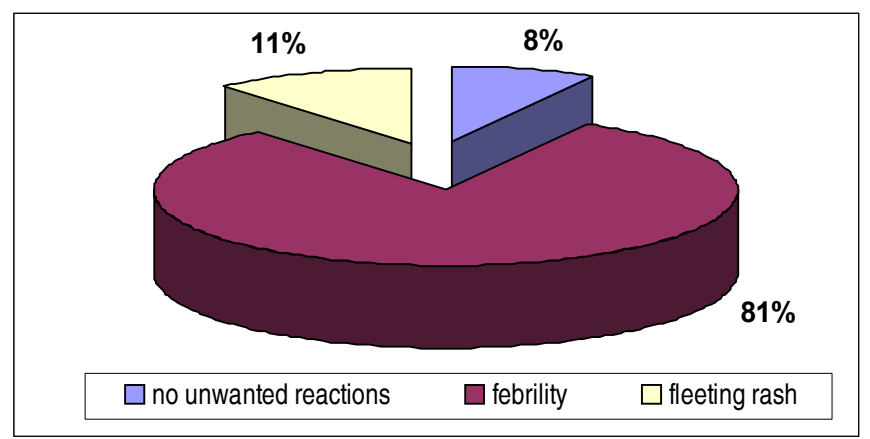

Undoubtedly, much more serious are the complications among patients recovering from mumps, reported the interviewed physicians - Fig.3.

Fig. 3. Observed complications after a parotitis infection

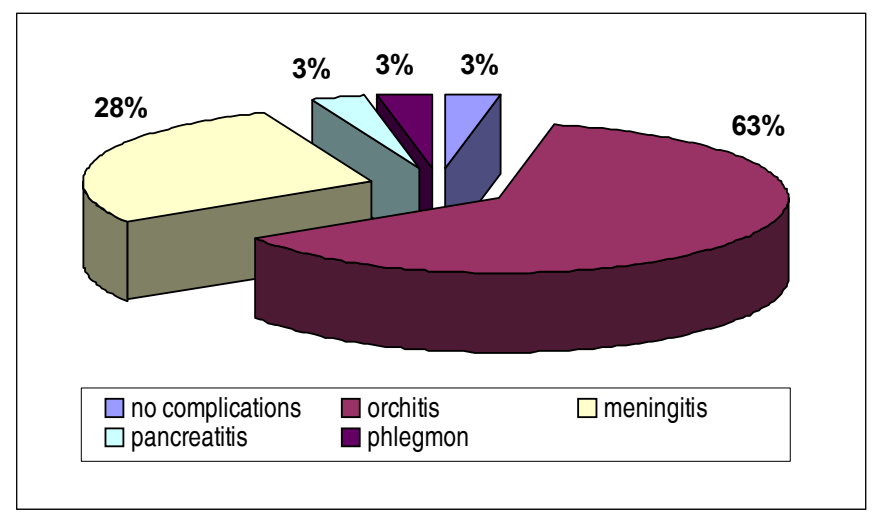

With respect to diagnostics of the disease, most of the participants in the research, report to have had no difficulties whatsoever, a smaller part - about $12 \%$ faced difficulty because of an indistinct clinical picture, $16 \%$ had difficulty in conducting laboratory researches because of the location of their workplaces. Such answers were given by doctors working in the villages and smaller towns $(\chi=11,42 ; \mathrm{p}=0,0222)$.

About 3\% replied to have had difficulties both in determining the clinical picture and conducting the researches.

In the event of an occurred disease, a considerable part of the interviewed physicians announce to always send the patients to a specialist in infectious diseases - $37 \%$, and $55 \%$ consult a specialist in infectious diseases only if complications occur - regardless of the experience of the GP $(\chi=0,29 ; p=0,8654)$ and his/her workplace $(\chi=3,16$; $\mathrm{p}=0,5313)$. 


\section{CONCLUSION:}

On the grounds of the research conducted we can conclude that the campaign again the disease has to be directed to entire vaccination of the susceptible population, promotional activities among the risk population groups, early and active search of the sick with mumps, dispensary observation of patients with complications. The general practitioners, considered to be the first unit in the health care system of the country, are the basic participants in the prevention of that disease by executing the immunization schedule.

\section{REFERENCES:}

1. Allen S., et al., The European definitioun of general practice/Family medicine, WONKA EUROPE, 2002, P 921

2. Bentsen B., The role of the general practitioner in health care. Tidsskr Nor Laegeforen, 1993, 113/29, p 3585-9
3. Gupta R., et al, Mumps and the UK epidemic 2005, BMJ, London: May 14, 2005, Vol. 330, lss.7500; pg. 1132

4. Hviid, A., et al., Mumps, Lancet 2008 Mar 15; 371(9616): 932-44, MEDLINE

5. Kojouharova, M., et al., Mumps outbreak in Bulgaria, 2007: a preliminary report, Eurosurveillance, Volume 12, Issue 12, 22 March

6. Peltola H., et al., Mumps outbreaks in Canada and the United States: time for new thinking on mumps vaccines, Clin Infect Dis. 2007 Aug 15; 45 (4): 459-66

Address for correspondence:

Ts. Valentinova, MD, $\mathrm{PhD}$,

Sector „General Medicine”, Medical University - Pleven,

1, Sv. Kliment Ohridski, Str., 5800 Pleven, Bulgaria

e-mail: tsvm2002@yahoo.com 